\title{
Spermiological Profile of Patients with Varicocele in Cotonou
}

\author{
Dodji Magloire I. Yevi*, Hamid Fagbemi, Jean Sossa, Michel Michaël Agounkpe, \\ Gilles Natchagande, Josué D. G. Avakoudjo, Prince Pascal Hounnasso
}

National University Teaching Hospital Hubert Koutoukou MAGA of Cotonou, Cotonou, Benin

Email:*dryevi@gmail.com

How to cite this paper: Yevi, D.M.I., Fagbemi, H., Sossa, J., Agounkpe, M.M., Natchagande, G., Avakoudjo, J.D.G. and Hounnasso, P.P. (2017) Spermiological Profile of Patients with Varicocele in Cotonou. Open Journal of Urology, 7, 40-46. https://doi.org/10.4236/oju.2017.72006

Received: August 11, 2016

Accepted: February 4, 2017

Published: February 7, 2017

Copyright (C) 2017 by authors and Scientific Research Publishing Inc. This work is licensed under the Creative Commons Attribution International License (CC BY 4.0).

http://creativecommons.org/licenses/by/4.0/

\begin{abstract}
Objective: To evaluate the effects of varicocele on sperm characteristics, on testicles and its responsibility in male fertility. Patients and Methods: The study took place in the National University Teaching Hospital Hubert Koutoukou Maga of Cotonou. It was a prospective study, from December 2015 to July 2016, which concerned 45 patients affected by the varicocele and seen for infertility. The duration of the infertility was 12 months or more, according to the definition. The studied parameters were the age, the profession, the deadline of the infertility, the type and the rank of the varicocele, the data of the ultrasound and the spermogram. Results: The average age of our patients was 35 years with a range of 20 and 56 years. The average duration of infertility was 3 years and 5 months. The pattern of consultation was a desire of paternity in $71.1 \%$ of cases. The testicular hypotrophy was found in $93.3 \%$ of cases at the right side and in $97.8 \%$ at the left side. The varicocele was bilateral at $82.2 \%$ of cases. The most frequent sperm abnormality was the oligoasthenoteratozoospermia found in $31.1 \%$ of cases. Conclusion: The varicocele is a male subject pathology. Its consequences on fertility are bad as well as on the volume and the capacity of the testicles to play its endocrine and exocrine function. The better choice is to start the treatment just when it is found in a man. The surgery seems to be the best solution to that important social problem.
\end{abstract}

\section{Keywords}

Varicocele, Cotonou, Spermiological Profil, Male Infertility

\section{Introduction}

Varicocele is a varicose dilatation of the pampiniform plexus veins after a renospermatic venous reflux by valvular insufficiency. It can lead to discomfort or scrotal pain, testicular atrophy or infertility. Infertility is defined as the inability 
for a couple to get pregnant after a year of complete, frequent and regular sexual intercourse, without contraception. Couple infertility affects around 15\% of couples. Generally, it is said that its origin is from the men only in one third of cases, from the women only in one third of cases and from the two in the last one third of cases. A cause of male origin is found in $30 \%$ to $40 \%$ of cases [1] [2]. The opinions diverge about the role of varicocele in the occurrence of infertility in men. The understanding of the varicocele impact on male reproduction health is necessary to justify the decision of surgical treatment in order to make a gain in the management of the infertile couple [3] [4] [5]. The objective of this study is to evaluate the effects of varicocele on sperm characteristics, on testicles and its responsibility in male fertility.

\section{Patients and Methods}

The study took place in the National University Teaching Hospital Hubert Koutoukou Maga of Cotonou. It was a prospective study over a period of 8 months, from December 2015 to July 2016, on 45 patients affected by varicocele and who consulted for infertility. The duration of infertility was 12 months or more, according to the definition. Patients with infra clinical varicocele were not taken into account. The parameters studied were: Epidemiological: age, occupation, period of infertility.

Clinical: type and duration of infertility, history, clinical examination.

The detected varicoceles were classified into 3 grades: Grade 1: palpable varicocele during the Valsalva maneuver, grade 2: varicocele invisible but palpable at rest, grade 3: varicocele visible and palpable at rest.

Para clinical: ultrasound of scrotal contents; testicular volume was measured with ultrasound according to Lambert formula (length $\times$ width $\times$ height $\times 0.71$ ) [6]. A volume equal to $16 \mathrm{cc}$ was considered as normal. A stratification was made and allowed to classify into: mild hypotrophy (volume between $13 \mathrm{cc}$ and $15.99 \mathrm{cc}$ ), moderate hypotrophy (volume between $9 \mathrm{cc}$ and $12.99 \mathrm{cc}$ ) and severe hypotrophy (less than $9 \mathrm{cc}$ ).

The data of semen analysis explored were: sperm count, mobility, volume, $\mathrm{pH}$, spermoculture. The collection of the semen was performed after masturbation or after coitus interruptus. The abstinence period was 3 days. The analysis of semen data was done according to the norms of WHO 2010 [7]. Two semen analyzes were applied consistently to all patients. They were made in two different laboratories at the option of the patient and at least two months apart. Data collection was done on the basis of a survey containing all the parameters to be studied before being introduced in the software Epi Info 7. The results were analyzed by the same Epi data processing software info 7. The graphics were generated by Excel 2007 software.

\section{Results}

We collected a total of 45 records of patients over 8 months. All the men were married and/or living in a relationship with at least one woman. The minimum 
duration of life in couple was 12 months. The average age of the men was 35 years, ranging from 20 years to 56 years. $57.8 \%$ of patients were aged between 31 and 40 years. The distribution by age groups is shown in Figure 1 .

The mean duration of infertility was 41.3 months (3 years 5 months) with extrems of 12 and 300 months (25 years). 60\% of patients who consulted had an infertility duration between 1 and 2 years against $17 \%$ for the duration from 5 to 25 years. The distribution of patients according to the duration of infertility is represented in Figure 2.

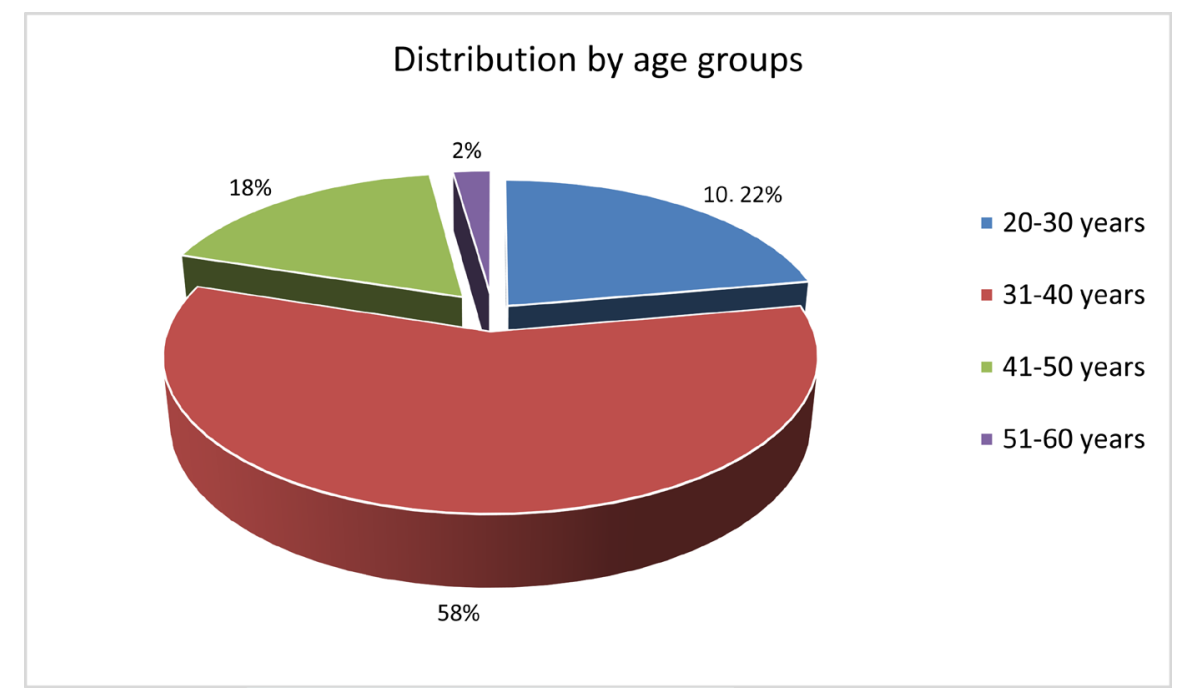

Figure 1. Distribution by age groups.

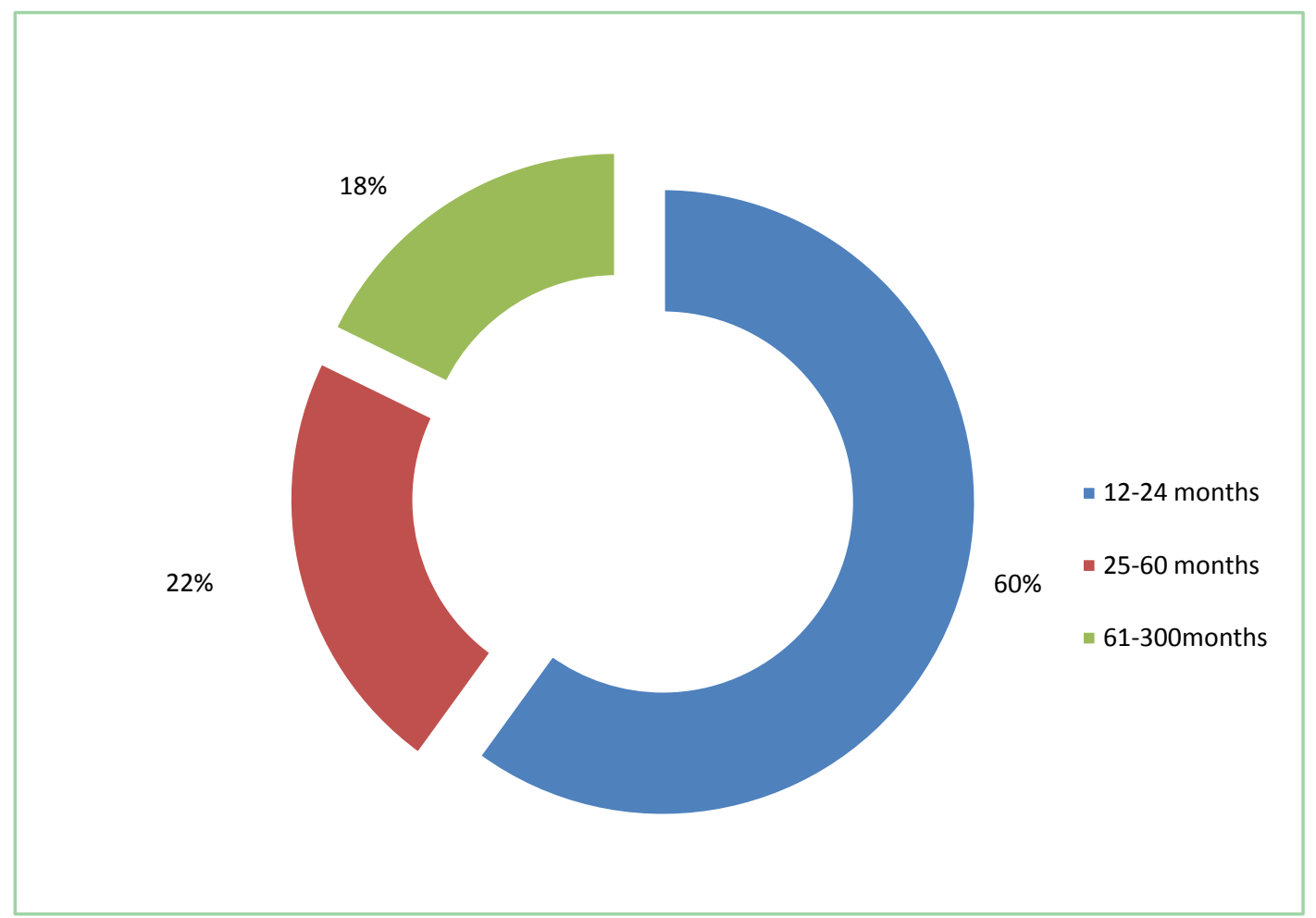

Figure 2. Distribution by duration of infertility. 
The chief complaint was a paternity desire in $71.1 \%$ of cases. $8.9 \%$ of patients had consulted for testicular pain which is another common sign in case of varicocele. Patients who consulted for varicocele were referred by a physician or were seen by appointment for their support. So they had already seen at least once before the study period. The distribution of patients according to the reason for consultation is shown in Table 1.

In this study, $68.9 \%$ of patients had primary infertility while $31.1 \%$ had secondary infertility. Ultrasound performed in patients showed right testicular hypotrophy in $93.3 \%$ of cases and the left in $97.8 \%$ of cases (Figure 3 ).

The distribution of patients by degree of varicocele is shown in Table 2.

Varicocele was bilateral in $82.2 \%$ of patients and found only at left in $15.6 \%$ of cases. Only one patient (2.2\%) had a varicocele found only on the right. According to sperm count, patients were divided into 3 groups: Azoospermia: absence of sperm, oligospermia: less than 15 million normal count: $\geq 15$ million.

Table 1. Breakdown by reason for consultation.

\begin{tabular}{ccc}
\hline Reason for consultation & Frequency & Poucentage \\
\hline Paternity desire & 32 & $71.11 \%$ \\
Testicular pains & 4 & $08.89 \%$ \\
Varicocele & 8 & $17.78 \%$ \\
Painful erection & 1 & $02.22 \%$ \\
Total & 45 & $100.00 \%$ \\
\hline
\end{tabular}

Table 2. Frequency of varicocele in the study population.

\begin{tabular}{ccc}
\hline Varicocele degree & Frequence & Pourcentage \\
\hline Degree 1 & 5 & $11.1 \%$ \\
Degree 2 & 19 & $42.2 \%$ \\
Degree 3 & 21 & $46.7 \%$ \\
Total & 45 & $100 \%$ \\
\hline
\end{tabular}

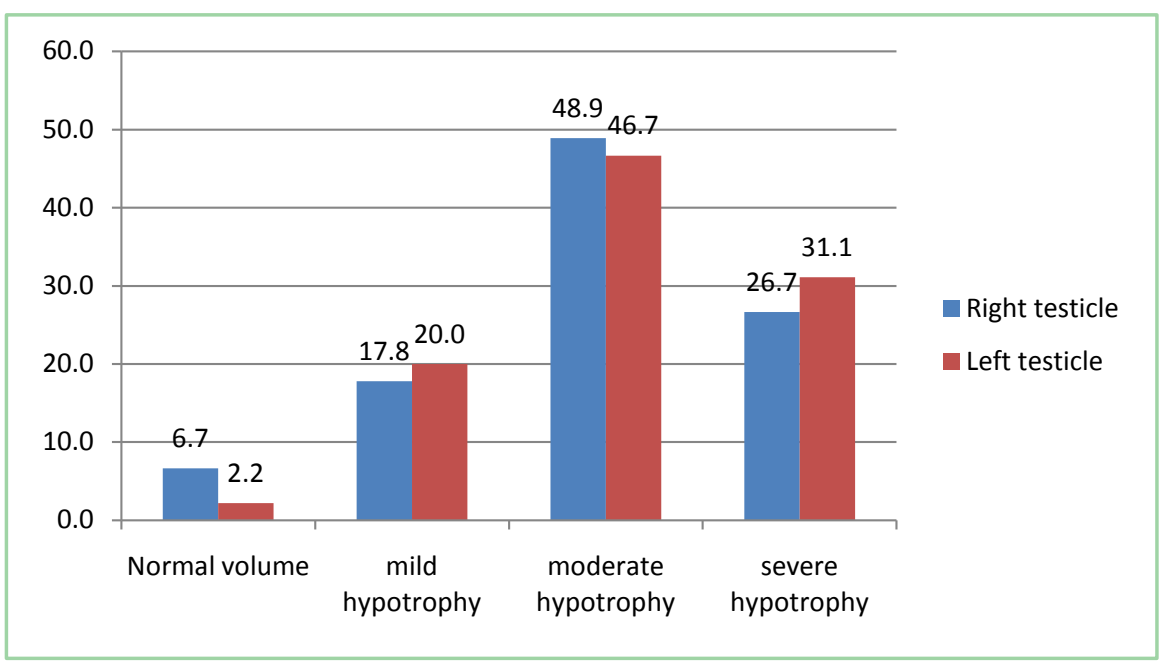

Figure 3. Distribution by testicular volume (\%). 
The distribution of patients according to the sperm count is shown by Figure 4 .

On the 24 patients with oligospermia, 54.2\% had severe oligospermia and 29.2\% had moderate oligospermia with a range between 5 and 10 millions sperms. $17.8 \%$ of patients had teratospermia. The most frequent pathological combination was trace asthénotératozoospermia found in $31.1 \%$ of cases The ph was normal in $66.7 \%$ of cases and pathological in $33.3 \%$.

\section{Discussion}

The average age of patients in our study was 35 years, ranging from 20 years to 56 years. $57.8 \%$ of patients were aged between 31 and 40 years. These results are similar to those obtained by Elbardishi et al. [8] in Qatar where they found an average age of 36.3 years. Diao and et al. in Senegal [5] noted an average age of 36.5 years. But they are well beyond the result found by Benazzouz and et al. [6] in Morocco, which was 29.71 years.

The most represented age group was the 31 to 40 years. This results in our context would be due to later consultation of our people in general and in particular to ignorance of the patients about the disease and a specialty of Urology in Benin. This also justifies the long duration of disease progression prior consultation was 25 years with an average duration of 3 years and 5 months.

The chief complaint was a paternity desire in $71.1 \%$ of cases and $68.9 \%$ of patients had primary infertility unlike $62.4 \%$ of cases found by Diao [5]. Testicular pain was found in only $8.9 \%$ of cases. 8 patients had consulted for varicocele and were directed by a doctor. The diagnosis in other patients seen for infertility was made after clinical examination and confirmed by ultrasound. Varicocele is considered as a disease causing a progressive deterioration of semen analysis and testicular volume [1]. This was evidenced by Glass berg [9], and Pathak et al. [10]. That proves why the alteration of semen analysis and testicular stunting is higher in the age group 31 to 40 and 41 to 56 years compared to youngers [1] [6] [11]. But according to Pathak's study, it is more important in primary infertile group (68.9\%). This reinforces the belief that there is an interest for young age patients with varicocele to keep their sperm for medically assisted reproduction

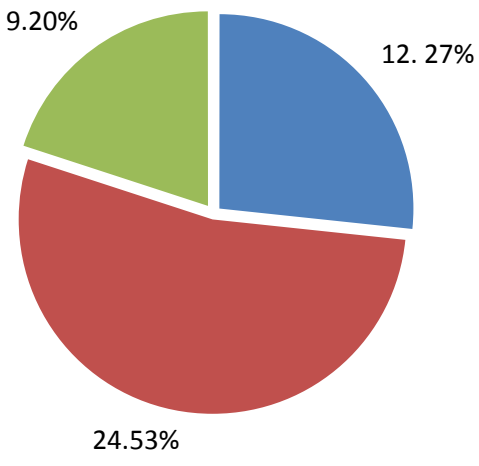

Azoospermia

- Oligospermia

Normal count

Figure 4. Distribution sperm count. 
or artificial insemination [6] [10] [12]. Several theories have been advanced to explain the mechanism of impaired sperm parameters in case of presence of varicocele: increasing temperature in the testicles, local hypoxia by stagnation of poor venous blood oxygen and toxic metabolites from kidney or adrenal. The theory about the increase of intra scrotal temperature was demonstrated from an experimental model and affects both testicles even if the varicocele is unilateral [1] [13] [14].

Varicocele was bilateral in $82.2 \%$ of patients and found only on left in $15.6 \%$ of patients. One patient $(2.2 \%)$ had isolated right varicocele. Our results are very similar to those of Diao and et al. [5] and underpin the argument that the varicocele should be regarded as a bilateral pathology and should be treated as such [1]. The observed alterations in spermatogenesis would be the consequence of testicular atrophy observed in $93.3 \%$ of cases at right and in $97.8 \%$ of cases at left [2]. This atrophy was bilateral in $93.3 \%$. Testicular volume is an important marker of sperm production capacity and therefore is a prediction on sperm production [6] [11].

About the semen characteristics, oligoasthenoteratozoospermia is the pathological combination wich was the most frequently found. The same was found in the study did by Diao and et al. and Benazzouz and et al. [4] [9]. The rate of $31.1 \%$ obtained in our study were higher than the $20.51 \%$ found by Benazzouz and et al. but well below the $63.2 \%$ reported by Diao et al. [5]. These results could be explained by the high rate of azoospermia obtained which was $27 \%$.

\section{Conclusion}

Varicocele is a male surgical pathology which seems banal. Its impact is important in the population of infertile men and the consequences could be dramatic for male fertility and the survival of the couple. The deterioration of sperm quality and testicular atrophy is progressive, and it then proves to be important to organize early treatment as soon as the indication is asked to preserve the fertilizing capacity of man and a proper monitoring of the patient.

\section{References}

[1] Cho, C.-M., Esteves, S.C. and Agarwal, A. (2016) Novel Insights into the Pathophysiology of Varicocele and Its association with Reactive Oxygen Species and Sperm DNA Fragmentation. Asian Journal of Andrology, 18, 186-193. https://doi.org/10.4103/1008-682X.170441

[2] McGuire, D.R. (1991) Male Infertility. In: Smith's General Urology, 12th Edition, 489-718.

[3] Nevoux, P., Robin, G., Gonheim, T., Boitrelle, F., Rigot, J. and Marcelli, F. (2009) Varicocèle et infertilité: Mythe ou réalité ? Progrès FMC, Le point sur... 19, 4, F126-F130.

[4] Benazzouz, M.H., Essatara, Y., El Sayegh, H., Iken, A., Benslimane, L. and Nouini, Y. (2014) Impact de la varicocèle sur le volume testiculaire et les paramètres spermatiques. Service d'Urologie A, Hopital Ibn Sina, CHU Rabat, Maroc. The Pan African Medical Journal, 19, 334. https://doi.org/10.11604/pamj.2014.19.334.4693 
[5] Diao, B., Sy, M.R., Fall, B., Sow, Y., Sarr, A., Mohamed, S., Sine, B., Fall, P.A., Ndoye, A.K., Ba, M. and Diagne, B.A. (2012) Varicocèleetinfertilité masculine. Andrologie, 22, 29-35.

[6] Sakamoto, H., Yajima, T., Nagata, M., Okumura, T., Suzuki, K. and Ogawa, Y. (2008) Relationship between Testicular Size by Ultrasonography and Testicular Function: Measurement of Testicular Length, Width, and Depth in Patients with Infertility. Japan International Journal of Urology, 15, 529-533.

[7] Cooper, T.G., Noonan, E., Eckardstein, S., Auger, J., Baker, H.W.G., Behre, M.H., Haugen, T.B., Kruger, T., Wang, C., Mbizvo, M.T., Kirsten, T. and Vogelsong, M. (2010) World Health Organization Reference Values for Human Semen Characteristics. Human Reproduction Update, 16, 231-245.

https://doi.org/10.1093/humupd/dmp048

[8] ElBardis, H., Arafa, M., Rengan, A.K., Durairajanayagam, D., AlSaid, S.S., Khalafalla, K., AlRumaihi, K., Majzoub, A. and Agarwal, A. (2016) Varicocele among Infertile Men in Qatar. Andrologia, 12 July. https://doi.org/10.1111/and.12637

[9] Glassberg, I.K. (2014) My Indications for Treatment of the Adolescent Varicocele (and Why?) Translational Andrology and Urology, 3, 402-412.

[10] Pathak, P., Chandrashekar, A., Hakky, T.S. and Stuszak, A.W. (2016) Varicocele Management in the Era of in Vitro Fertilization/Intracytoplasmic Sperm Injection. Asian Journal of Andrology, 18, 343-348. https://doi.org/10.4103/1008-682X.178482

[11] Pastuszak, A.W. and Wang, R. (2015) Varicocele and Testicular Function. Asian Journal of Andrology, 17, 659-667. https://doi.org/10.4103/1008-682X.153539

[12] Keene, D.J., Sajad, Y., Rakoczy, G., et al. (2012) Testicular Volume and Semen Parameters in Patients Aged 12 to 17 Years with Idiopathic Varicocele. Journal of Pediatric Surgery, 47, 383-385. https://doi.org/10.1016/j.jpedsurg.2011.11.035

[13] Gorelick, J.L. and Goldstein, M. (1993) Loss of Fertility in Men with Varicocele. Fertility and Sterility, 59, 613-616. https://doi.org/10.1016/S0015-0282(16)55809-9

[14] Goldstein, M. and Eid, J.F. (1989) Elevation of Intratesticular and Scrotal Skin Surface Temperature in Men with Varicocele. The Journal of Urology, 142, 743-745.

\section{Submit or recommend next manuscript to SCIRP and we will provide best service for you:}

Accepting pre-submission inquiries through Email, Facebook, LinkedIn, Twitter, etc. A wide selection of journals (inclusive of 9 subjects, more than 200 journals)

Providing 24-hour high-quality service

User-friendly online submission system

Fair and swift peer-review system

Efficient typesetting and proofreading procedure

Display of the result of downloads and visits, as well as the number of cited articles

Maximum dissemination of your research work

Submit your manuscript at: http://papersubmission.scirp.org/

Or contact oju@scirp.org 